\title{
Abandono e Adoção como Direito Fundamental E ADOÇÃo INTERNACIONAL COMO EXCEÇÃO NO NORDESTE BRASILEIRO
}

\author{
Gizela Nunes da Costa* \\ José Edmar da Silva Ribeiro**
}

1 Introdução. 2 O Menor Abandonado. 3 O Meio Social Adverso 3.1 A Pobreza. 4 O Exodo Rural. 5 A Adoção. 6 A Adoção Internacional como Exceção. 7 Conclusão. Referências.

\section{RESUMO}

Este artigo trata do instituto da adoção como direito fundamental e da adoção internacional como exceção, considerando, mais especificamente, a situação do menor abandonado no Nordeste brasileiro. Para fomentar a metodologia deste estudo, foi realizada a pesquisa bibliográfica com análise de obras, da legislação e de dados estatísticos. Aborda os possíveis danos causados pela institucionalização, refletidos diretamente na sociedade, pois a criança inserida em abrigos sofre com a limitação ou, até mesmo, com a ausência de valores, estímulos, convivência e segurança, sendo, esta última, um direito fundamental do infante. Contextualiza o meio social adverso e hostil da região Nordeste do país. Destaca a condição de penúria das famílias nordestinas, que, muitas vezes, sem alternativa, deixam os filhos em portas de residências, abrigos, chegando até a abandoná-los em hospitais ou em postos de saúde. A adoção é entendida como um instituto excepcional para integrar a criança e o adolescente ao convívio familiar estável e seguro e se refere ao conjunto normativo que trata da matéria: Convenção sobre os Direitos da Criança (CDC), Constituição Nacional de 1988 e Estatuto da Criança e do Adolescente (ECA). Conclui-se que a adoção internacional, como exceção, cercada das cautelas legais, oferece a crianças e a adolescentes abandonados um futuro promissor, além de melhores condições de crescimento em comparação aos orfanatos, além de reduzir o tempo de espera para reintegração familiar. Diferentemente dos adotantes brasileiros, mais seletivos, a adoção feita por estrangeiros é livre de preconceitos e sem preferências.

Palavras-chave: Direitos Humanos. Abandono. Institucionalização. Adoção. Exceção. Adoção Internacional. Tendência. Nordeste brasileiro.

* Desembargadora do Tribunal de Justiça do Ceará. Professora Universitária. Da Academia Fortalezense de Letras e Presidente da Associação dos Jornalistas e Escritoras do Brasil - Ceará. E-mail: <gizelanunes.39@ gmail.com >. https://orcid.org/0000-0002-8738-9164

** Procurador Federal. Professor Universitário. Jornalista. Da Academia Cearense de Cinema. Diretor Editorial da Revista APESCultura da Associação de Professores de Ensino Superior do Ceará. E-mail: <1edmar. ribeiro@gmail.com>.https://orcid.org/0000-0003-2312-309X 


\section{INTRODUÇÃO}

A Carta Máxima de nosso País (art. 227) (BRASIL, 1988) determina que as crianças e os adolescentes têm assegurado o direito à convivência familiar. Assim, a sua efetivação é obrigação da família e da sociedade. Evidentemente a usufruição deste resulta da necessidade dos fundamentos da construção das bases fundamentais saudáveis para a construção e o desenvolvimento da personalidade e das potencialidades deles.

Inegavelmente o ambiente familiar é a célula-mater para o completo desenvolvimento do cidadão. A falta deste ou a falha do sistema que o abriga e o mantém desmorona o arcabouço da unidade central e deixa ao largo toda a rede de cuidados familiares que sustenta o bem-estar do infante. Na esteira da desagregação física e moral do núcleo familiar, acorrem várias circunstâncias deletérias, aproveitando-se desse vácuo de cuidados, como o abandono puro e simples, chegando, por vezes, ao tráfico ou ao infanticídio.

Trata-se aqui do mecanismo de modelos adotivos, como substituto adequado para contornar males maiores, confrontando com a possibilidade da adoção internacional como subsidiária e secundária, diante do preferencial modelo, disponíveis aos nacionais adotantes.

Com referência à metodologia do trabalho, utiliza-se a pesquisa bibliográfica, mediante leitura e análise de obras, da legislação vigente, da pesquisa bibliográfica e dos dados estatísticos referentes à matéria.

Analisam-se, então, fatos além da convivência familiar precípua, no âmbito da adoção nacional e internacional. Assim, torna-se necessária essa abordagem, dada a relevância do assunto no que se refere ao impacto social, especialmente em nossa região, dadas as condições adversas de sobrevivência dos menos favorecidos.

Até a década passada, nossa população era composta, em sua grande maioria, por crianças e adolescentes o que mais releva a necessidade de se dedicar mais importância e constância ao estudo da matéria. Embora essa tendência tenha sido alterada com a maior expectativa de vida da população (INSTITUTO BRASILEIRO DE GEOGRAFIA E ESTATÍSTICA, 2011), permanece relevante a necessidade de dedicar-se mais importância e constância no estudo da matéria.

É consabido que a situação de abandono é suportada por indivíduos com menos de 18 anos (INSTITUTO DE PESQUISA ECONÔMICA APLICADA, 2012), e a adoção, por regra de dispositivos legais, surge como um meio de proporcionar a inserção em um núcleo familiar. Ocorre que, na maioria dos estados, em especial no Ceará, a preferência dos adotantes nacionais inclina-se por um perfil que não se enquadra nos disponíveis para adoção. Nessa condição, surge o instituto da adoção internacional como a alternativa para os que são preteridos pelos nacionais, pois os adotantes não se mostram sensíveis às características refutadas pelos nacionais.

No tópico inaugural, tece-se consideração sobre a realidade da situação de abandono do menor frente à necessidade de convívio familiar. No seguinte, comenta-se sobre a adversidade do meio social no qual está inserido, comprometido frente às condiç̃oes socioeco- 
nômicas advindas do ambiente hostil proporcionado pela estiagem ou seca constante e, às vezes, cíclicas. No tópico terceiro, comenta-se sobre as consequências advindas do êxodo rural. No quarto tópico, aborda-se o mecanismo da adoção como meio de inserção em família substituta e, no seguinte, a forma internacional como exceção.

\section{O MENOR ABANDONADO}

"Muitas coisas que nós precisamos podem esperar. A criança não pode. Agora é o tempo em que seus ossos estão sendo formados; seu sangue está sendo feito; sua mente está sendo desenvolvida. Para ela nós não podemos dizer amanhã. Seu nome é hoje." (Gabriela Mistral).

O abandono de crianças não pode ser desvinculado do tema dos direitos humanos e, sobretudo, não pode ser entendido sem considerar o ambiente socioeconômico frente às políticas governamentais disponibilizadas à população que leva esse quadro a ser composto de ações insuficientes para proporcionar uma paz social e existência, no mínimo, decente e digna.

Em termos de normatividade, há de se considerar que, em 1959, foi posta em vigência a Declaração dos Direitos da Criança pela Organização das Nações Unidas, a qual dispôs sobre um arcabouço ético mínimo para a criança desprotegida e indefesa. Já em 1989, a Convenção Internacional dos Direitos da Criança estabeleceu um arcabouço jurídico mais denso, convalidado pela maioria das nações. Destacou-se, ainda, que um dos principais direitos fundamentais é o da convivência em família e em comunidade.

Nossa Carta Máxima estabelece a proibição de tratamento diferenciado entre os filhos, dando proteção especial à família formada pelos liames de afeição, configurados pelos cuidados, pelo carinho e pela proteção. Ademais, a relação de paternidade, no lúcido entender de Rodrigues (2005, p. 3-4), desponta o afeto:

[...] como quesito apto a determinar a verdadeira relação de paternidade, posto que exercida com a responsabilidade idealizada pela lei.[...] Mas o afeto de que se trata não pode ser confundido com a noção da affectio, presente já no modelo romano. Esta, no modelo patriarcal, era presumida e condicionada à existência de uma situação juridicamente reconhecida: o casamento trazia consigo a affectio maritalis, que justificava a necessidade de continuidade da relação. Já o afeto entende-se como vontade de estar e permanecer junto a alguém. Tempos atuais novos valores, a affectio maritalis traduz-se hoje como um valor socioafetivo que funda uma sociedade conjugal, matrimonializada ou não.

Nesse sentido, é o princípio da afetividade que advém no Direito familiar a par da base constitucional, nivelando as condições filiares biológicas e as não biológicas. Nasce tal primado, destaque-se, dos postulados maiores da convivência familiar harmônica e principalmente do norte da obrigatória posse da dignidade humana, contribuindo, poderosa e fundamentalmente, para a integridade e a incolumidade no processo da formação plena da cidadania. No dizer de Welter (2005, online, grifo do autor), entende-se que: 
A verdadeira filiação, na mais moderna tendência do direito internacional, só pode vingar no terreno da afetividade, da intensidade das relações que unem pais e filhos, independente da origem biológico-genética [...] [LEITE, 1994, p. 121] Por isso, imponderável a idealização da diferença jurídica entre os filhos biológico e afetivo, porquanto são identificados como membros de uma família, os quais, perante a Constituição Federal de 1988, são iguais em direitos e obrigações [WELTER, 2003].

A noção de menor abandonado alterou-se no decorrer dos tempos. Até meados da década de 1970, entendia-se que esse ato era considerado, nesse estado, por desídia ou orfandade familiar. Como solução proposta, a criança era conduzida a abrigos e tratada para integrar-se à sociedade. Já na atualidade, compreende-se que a inserção e a permanência da criança nas ruas são motivadas pela busca de um meio de sobrevivência, e não necessariamente somente pelos motivos já citados. A criança, na realidade, realiza trabalhos (mendicância, pequenos furtos e outras práticas infracionais), mas retorna a suas famílias com o produto dessas ações, por exemplo, a própria família participar das ações é um caso comum que ilustra esse posicionamento.

A inserção da criança em abrigos, na maioria das vezes, gera a falta de interesse das famílias em acolhê-la de volta à sociedade, e ela chega à maioridade sabendo que pertence a um núcleo familiar, mas sem ter tido condições de alcançar os seus valores, a convivência e a segurança, que se trata de um direito fundamental do infante.

É o mecanismo da institucionalização, gerada com o entendimento central de que, segundo Lima e Veronese (2012, p. 33),

Crianças e adolescentes pobres, ditos menores, não eram possuidores de direitos, eram considerados meros objetos e estavam à disposição do Estado, que, representado no Poder Judiciário, encontrou na internação a na solução pedagógica meios viáveis para resolver os conflitos urbanos e o problema da criminalidade.

Dessa forma, com a institucionalização permitida pela lei, os menores foram retirados das ruas e do convívio de seus familiares, com a inserção e o confinamento em instituições disciplinares, para serem moldados e adaptados aos padrões socialmente postos, à vista de uma ressocialização futura, tida como oportuna e adequada.

A doutrina mais respeitada entende que essa institucionalização é danosa e condenável, pois não apresenta condições nem materiais de acolhimento nem muito menos oferece o mínimo elo familiar fundamental: "o ato da institucionalização é em si mesmo uma forma de abuso infantil.” (MILLER, 1981, p. 13). No mesmo sentido:

Apesar desse conhecimento acumulado - que se revela como algo induvidoso neste início de novo milênio - ainda se mantém, no imaginário coletivo de boa parte da sociedade contemporânea, a cultura da institucionalização de crianças e adolescentes - fruto de uma prática política muito difundida ao longo da história brasileira - como medida de enfrentamento das mazelas e escassez de recursos econômicos das famílias afastadas da partilha dos meios de produção nacional, ou como forma de disciplinar e torná-las governáveis (ABREU; MARTINEZ, 1997 apud FACHINETTO, 2008, p. 55).

A recente Lei $n^{\circ}$ 13.509/2017 (BRASIL, 2017) tem o objetivo de não somente acelerar e buscar a otimização do procedimento na colocação de crianças e infantes em famílias substitutas, mas, ainda, em meta mais ampla, de alterar a política de institucionalização do infante. 
Advieram outras alterações significativas: a) se for mãe uma adolescente em acolhimento institucional, terá direito a uma convivência integral com o filho (art. $19, \S \S 5^{\circ}$ e $6^{\circ}$ ); a entrega do infante pelas mães ficou mais facilitada, com o encaminhamento ao juizado da mãe, com acompanhamento especializado (art. 19-A, caput, $\S \S 1^{\circ}$ e $2^{\circ}$ ); no que diz respeito à preferência pela família biológica, estabeleceu-se que, se a mãe nominar o pai da criança, haverá a tentativa para que este assuma a guarda e as suas responsabilidades de genitor (art. 19-A, $\S 3^{\circ}$ ). Em caso de não indicação, sem algum representante familiar apto para tal, o juiz determinará a extinção do poder familiar, designando que o infante seja posto sob guarda provisória a quem estiver habilitado para tal (idem $\S 4^{\circ}$ ); e foi inserido um interessante instituto, o de apadrinhamento (art. 19-B), que é uma forma alternativa para desinstitucionalizar o menor em situação de risco em acolhimento institucional ou em ambiente familiar, para que possa vir a formar vínculos afetivos com pessoas não ligadas a instituições ou à família acolhedora na qual vivam. A alteração do parâmetro temporal de permanência do menor, que passou de dois anos para dezoito meses, foi uma ação benéfica, e a intenção do legislador foi no sentido preventivo frente a um período maior em situações de risco e disponibilizar uma convivência familiar via acolhimento substituto (BRASIL, 2017).

Ainda em sede de institucionalização estendida, Cuneo (2009) entende que certamente esta conduta acarretará sérios danos para o desenvolvimento do infante, por falta de seu convívio doméstico:

A institucionalização prolongada impede a ocorrência de condições favoráveis ao bom desenvolvimento da criança. A falta de vida em família dificulta a atenção individualizada, o que constitui obstáculo ao pleno desenvolvimento das potencialidades biopsicossociais da criança (CUNEO, 2009, p. 422).

O lapso temporal acarreta a descontinuidade de vínculos familiares, e o hiato compreendido pela institucionalização e a consequente reinserção do infante ao meio social, com certeza, podem acarretar prejuízos irremediáveis tanto na ordem emocional, intelectual e social, com prejuízo imediato e indelével na formação sadia do indivíduo, quanto na harmonia do meio coletivo ao qual retornará.

Essa circunstância é extremamente perigosa ao fatalmente atingir o tecido social quando a criança é liberada do albergue que ocupa. O impacto da má-formação e o acompanhamento humanizado irão refletir diretamente na sociedade sem que, nessa altura da vida do já adulto, se possa reverter o quadro que a criança atingiu. Nesse sentido, não há mais conserto que possa amenizar pelo menos as carências e as más-formações nela instauradas. Mister concordar com Pilotti e Rizzini (1995, p. 41) quando afirmam que:

A institucionalização acarreta mais danos que benefícios para a maioria das crianças internas devido ao predomínio das seguintes características negativas no desenvolvimento do ser humano: impossibilidade de interação com o mundo exterior e consequente limitação da convivência social; invariabilidade do ambiente físico, do grupo de parceiros e das autoridades; planejamento das atividades externas à criança, com ênfase na rotina e na ordem; vigilância contínua; ênfase na submissão, silêncio e falta de autonomia. As consequências negativas deste processo - tanto 
para o indivíduo como para a sociedade - surgem dos graves e irreversíveis efeitos exercidos pela institucionalização sobre os afetados. Com efeito, a criança interna desenvolve uma autoestima extremamente baixa, caracterizada por uma imagem negativa de si mesma o que interfere no desenvolvimento normal das relações interpessoais. A inserção social destas crianças fica extremamente limitada.

Vale comentar que a saída do infante do meio institucional gera necessidade de atenção para os riscos na sua formação afetivo-familiar, que seguramente poderá incidir negativamente em seu caráter na inevitável interação com a Sociedade. Já na primeira infância, em relação ao possível dano visível, por um lado, entende Ajuriaguerra (apud ALMEIDA, 2004, p. 22) que "não haverá prejuízos à criança se esta romper os vínculos com a ama do abrigo até os 8 meses de vida", enquanto por outro, David e Appell (apud ALMEIDA, 2004) asseguram que, no lapso temporal de 8 e 15 meses, a criança não construiu um liame personalístico com sua cuidadora, mas, a partir daí, não poderá ser evitada a quebra desse vínculo primordial.

Em um abrigo governamental, é impossível recriar o habitat familiar original mesmo que esteja aparelhado com os meios necessários aos cuidados da criança e que tenha profissionais habilitados e devotados para tal, não poderá representar ou sequer simular o meio familiar, seja original, seja substituto. Costa (2018, online) comenta: "Na maioria dos abrigos, a identidade de cada abrigado fica muito comprometida, a privacidade é algo quase inexistente, pois tudo é coletivo. A atenção e o carinho individualizados são praticamente impossíveis. Isso compromete em muito o desenvolvimento saudável da criança."

\section{O MEIO SOCIAL ADVERSO}

A área do sertão nordestino é composta de clima tropical seco e se expande desde a margem direita do Rio Paranaíba (RN) até o Rio Itapicuru, englobando os estados do Piauí, Ceará, Rio Grande do Norte, Paraíba, Alagoas, Pernambuco, Sergipe e Bahia, chamado de Polígono das Secas.

O terreno árido e pouco produtivo, a vegetação e a fauna de pequeno porte, bem como, em especial, a ocorrência sempiterna das secas, com raras estações chuvosas generosas, fazem que o ambiente se apresente especialmente hostil e propiciador de constantes catástrofes econômicas e sociais.

O período de seca, que é - convenha-se - o mais recorrente e constante estado climático na região, possui e reflete-se em situações econômicas, política, sociais e culturais vindas há séculos. Além de sua onipresença, há de se considerar também a influência decisiva advinda da dependência do país a grandes metrópoles, ao retraimento da terra, à desapropriação inadequada, à imprópria distribuição de água, que, em conjunto, propicia o aproveitamento e a proliferação da chamada "indústria da seca" quando há a apropriação e o mau uso de recursos advindos para combater o flagelo.

O fenômeno da seca não é recente, e as consequências, bem como o seu combate foram alterados ao longo dos tempos. Como exemplo cronológico, veja-se:

Já nos anos 1583/1585, tem-se a primeira informação sobre o flagelo, contado pelo Pe. Fernão Cardin, em viagem pelo sertão. Ele diz: "uma grande seca e esterilidade na província 
e que 5 mil índios foram obrigados a fugir do sertão pela fome, socorrendo-se aos brancos" (CARDIN apud HISTÓRICO..., 2014, online).

Em 1915 repete-se, e essa ocorrência é magistralmente retratada no romance O Quinze, da romancista Rachel de Queiróz. No período de 1723/1727, com grande violência, o flagelo acontece, com a inativação da maioria dos engenhos. Houve, até mesmo, o pedido para que o Rei de Portugal enviasse escravos, pois os que aqui trabalhavam haviam morrido de fome.

Em 1877-1879, ocorreu um dos mais graves episódios no Nordeste: o estado do Ceará, com uma população de aproximadamente 800.000 habitantes, teve 120.000 migrando para a Amazônia e 68.000 para outros estados.

Adicionando-se às medidas já adotadas com a seca de 1908/1909, o Governo Central criou a Inspetoria Federal de Obras Contra as Secas (IFOCS). No período seco de 1945, em substituição, foi instalado o Departamento Nacional de Obras Contra as Secas (DNOCS). No interregno de 1977/1984, ocorreu o mais longo período de seca de que se tem notícia, foi uma real catástrofe que atingiu todos os campos de atividades, tanto extrativas quanto produtivas, com reflexão direta na harmonia social.

Infelizmente, com o passar dos séculos, o cenário continuou inalterado e passou por algumas intervenções, de alentadora esperança de sucesso, esporádicas, mas sem a eficácia que se requer.

Em época mais recente, 2012, a Região é novamente assolada pela pior seca dos últimos trinta anos, quando o meio produtivo foi praticamente inutilizado. Estimou-se que a queda da produção, em grande parte do Polígono das Secas, chegou ao limite de 91\%.

\subsection{A POBREZA}

A situação adversa do meio soma-se e cristaliza-se na consequência imediata da persistência da pobreza dominante há séculos no Nordeste.

Atualizando dados, citam-se exemplos de notações oferecidas pelo Instituto Brasileiro de Geografia e Estatística (IBGE), que, em 2016, divulgou uma pesquisa sobre a pobreza mais extrema, resumida no gráfico abaixo.

Gráfico 1 - Linha de Pobreza

\section{LINHA DE POBREZA}

Brasileiros que vivem com menos de US\$ 1,9 por dia, em \%

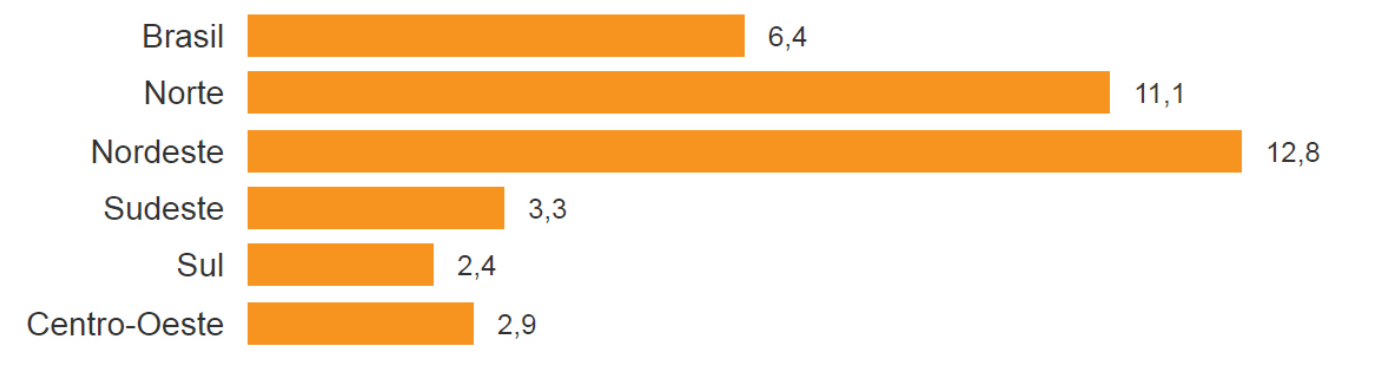

Fonte: (IBGE apud VETTORAZZO, 2017, online). 
A Organização das Nações Unidas (ONU) vai no mesmo sentido dessa constatação trágica. Estudo realizado pelo Centro Internacional de Políticas para o Crescimento Inclusivo (IPC-IG), vinculado ao Programa da ONU para o Desenvolvimento (PNUD), relata que, no período de 2004 a 2013, mesmo havendo decréscimo dos índices de pobreza (de 20\% para 9\%), "os principais aspectos ou perfis da pobreza continuam os mesmos: ela está mais presente no meio rural e nas regiões Norte e Nordeste do Brasil" (ORGANIZAÇÃO DAS NAÇÕES UNIDAS, 2016, online). Constata, ainda, que "A redução da pobreza não acompanhou as alterações em seus principais aspectos ou perfis", e, no geral, a situação continua caótica e desoladora, pois "Em termos regionais, pouco mudou, com as regiões Norte e Nordeste, apresentando as maiores taxas de prevalência da pobreza, bem como as áreas rurais em todas as regiões." (ORGANIZAÇÃO DAS NAÇÕES UNIDAS, 2016, online).

\section{O ÊXODO RURAL}

Em busca de condições mais favoráveis de vida, a população da zona rural desloca-se para a zona urbana, ação conhecida como o êxodo rural. Os motivos para esse deslocamento são os mais variados possíveis, o principal é compor o objetivo de melhoria de vida.

A fuga do flagelo das secas minando o tecido e a harmonia sociais, a busca de empregos, a mecanização da produção que substituiu a mão de obra, a procura de qualidade de ensino e a busca de atendimento a serviços essenciais, como hospitais, escolas, entre outros, são causas do fenômeno do deslocamento humano.

Com o aporte desse contingente absolutamente inabsorvível, as consequências nas cidades são desastrosas. Inicialmente, as dificuldades sociais com o aporte de tanta gente são a falta de emprego, acomodações, atendimento em serviços público que é insuficiente e inadequado a esse contingente extra. Por isso, ocorre o fenômeno da sobrevivência indigna dos migrantes, em todos os sentidos e as necessidades, por exemplo, na moradia, na educação, alimentação, entre outros que raiam aos mais ignóbeis baixos níveis de miséria.

Entre os problemas sociais, destaca-se a penúria das famílias, sem alternativa com relação aos filhos, "dados para criar" a famílias, postos em portas de residência, acomodados em abrigos para improvável adoção, ou simplesmente abandonados em hospitais ou postos de saúde. Essa opção não é utilizada no caso particular do flagelo da estiagem, mas, como constata Marcilio (1998, p. 135), essa queda é disseminada há muito tempo:

[...] mais universal e o mais abrangente, aquele que se estendeu por toda a história do Brasil, do século XVI aos nossos dias. Famílias ou indivíduos recolhiam recém-nascidos deixados nas portas de suas casas ou de igrejas, ou em outros locais e, por diversas razões, decidiam criá-los. Havia pessoas que iam as "rodas de expostos" tomar uma criança para criar e até mesmo perfilhar ou "adotar". São os chamados "filhos de criação".

Os municípios de origem do êxodo também sofrem com o deslocamento devido à diminuição de arrecadação de impostos, à insuficiência de produção agrícola e à crise social que pode provocar até a sua extinção. 


\section{A ADOÇÃO}

No mandamento constitucional, a garantia do direito ao convívio familiar, prioritariamente, dada às crianças e aos adolescentes é determinada como dever estatal, mas, muitas vezes, essa salvaguarda é descumprida, por isso surgiu como de suma importância para o Direito de Família o instituto da adoção, que inegavelmente proporciona-lhes a possibilidade de integrarem-se a uma família estável e segura, tendo como premissa maior o superior interesse da Criança. É esta que fundamenta e legitima as ações estatais em sua defesa, assim como toda uma gama de normas e procedimentos que lhe estejam harmonizados. Nessa perspectiva, Atalaio (2017, p. 48) lecionou:

O superior interesse da criança não está exclusivamente guiado para o bem-estar material ou financeiro, também se deve ponderar o desenvolvimento da criança de uma forma sã e equilibrada, em termos morais, educacionais, psicológicos e físicos. O que é fundamental é garantir o desenvolvimento harmonioso da criança, proporcionando-lhe as melhores oportunidades de estabilidade emocional, equilíbrio psíquico e condições para o seu futuro.

Em harmonia com essa prevalência, em remansosa sede jurisprudencial:

GUARDA DE FILHO. Prevalência do interesse da criança. - Criança com oito anos idade, que vive desde os primeiros meses de vida sob a guarda do pai e na companhia da avó paterna, que lhe oferecem boas condições materiais e afetivas, com estudo social favorável à conservação dessa situação. - Ação de guarda definitiva promovida pelo pai julgada procedente na sentença e na apelação, com reforma em grau de embargos infringentes. - Recurso especial conhecido e provido para restabelecer o acórdão proferido na apelação (BRASIL, 2003, online).

Exatamente por sua relevância, nossas normas legais têm regras para fiscalizar o processamento e para garantir e salvaguardar os direitos dos infantes, com atuação do Poder Judiciário, do Ministério Público, do Poder Executivo.

Tal princípio resguardador e protetivo é regra pétrea da Carta Magna, inscrita no caput do art. $6^{\circ}$, culminando, no art. 227, ser dever do Estado "colocá-los a salvo de toda a forma de negligência, discriminação, exploração, violência, crueldade e opressão." (BRASIL, 1988, online).

Sobre a Lei $\mathrm{n}^{\mathrm{o}} 12.010 / 2009$, alguns doutrinadores divergem, fazendo reparos sobre a garantia de sua eficácia. Nesse sentido, Dias (2010, p. 13) comenta que:

[...] a nova legislação, a qual tinha o objetivo de solucionar o problema de mais de 80 mil crianças e adolescentes institucionalizados à espera de um lar, não se presta para tal fim, porque, nada mais fez do que burocratizar e emperrar o direito à adoção de quem teve a desdita de não ser acolhido no seio de sua família biológica.

Com o mesmo sentimento, com precisão, completa Bodziak (2010, p. 30-31), abordando que: 
A convivência familiar [...] é concebida como um direito fundamental constitucional, principalmente por ser um espaço no qual a pessoa exercita sua dignidade e pela importância da vida em família como ambiente natural para o desenvolvimento daqueles que ainda não atingiram a vida adulta, seja na família natural ou substituta.

Pode-se reconhecer a adoção como um instituto excepcional para integrar uma criança em um meio familiar. Mesmo com esse entendimento, deve-se ter em mente que, antes desse instrumento ser aplicado, há a necessidade primordial de amparo, orientação e atenção às famílias carentes que abandonarem seus filhos por única e exclusiva falta de condições materiais. Evidentemente, o instituto poderá ser empregado secundariamente a outras premissas. Assim, é remansosa a Doutrina pátria, como o destacado entender de Alves (2011, p. 44):

[...] a adoção internacional era aquela pleiteada por estrangeiros residentes fora do país, sendo que agora alcança brasileiros residentes no exterior. Por oportuno, importante ressaltar que a adoção internacional sempre será supletiva à adoção nacional, ou seja, apenas quando forem esgotadas as possibilidades de colocação da criança ou adolescente em família substituta brasileira, após a consulta ao Cadastro Nacional.

Tratando de adoção, no Brasil, esse campo não diverge muito de qualquer país de nosso hemisfério ocidental. A acessibilidade a mecanismos de contracepção, as subvenções sociais e a alteração na moralidade sexual fizeram que as mulheres, mais e mais, elevem o status da maternidade e a criação de seu fruto, menos recorrendo ao mecanismo da adoção, resistindo a esta, por mais adversas que sejam suas condições socioeconômicas.

Exatamente por esse fenômeno recente (relevância da maternidade), torna-se visível e crescente a tendência de pessoas estarem vindo dos países mais desenvolvidos à procura de adotarem crianças.

Além de motivos levados pela incrível desigualdade social e financeira entre as classes sociais no Brasil, tem-se de considerar que a adoção, no Brasil, ainda carrega estigmas como casos evidentes de promovê-la mediante a clandestinidade. Sem contar com o fato de dificuldades e entraves legais, capeados pela preferência (ou preconceito) de cor e idade, havendo, ainda, a resistência da adoção de crianças portadoras de alguma deficiência.

Diante de disso, vale destacar o alerta de eminentes Doutrinadores sobre a realidade atual do instituto da adoção:

A doutrina na proteção integral e a vedação de referências discriminatórias na filiação (CF 227, $\S 6^{\circ}$ ) alteraram profundamente a perspectiva da adoção. Inverteu-se o enfoque dado à infância e à adolescência, rompendo-se a ideologia do assistencialismo e da institucionalização, que privilegiava o interesse e a vontade dos adultos. Agora a adoção significa muito mais a busca de uma família para uma criança. Foi abandonada a concepção tradicional, em que prevalecia sua natureza contratual e significava a busca de uma criança para uma família (DIAS, 2005, p. 426-427). 
No mesmo sentido:

Dada grande evolução verificada nas últimas décadas sobre o assunto, concebe-se atualmente a definição mais no sentido natural, isto é, dirigido a conseguir um lar a crianças necessitadas e abandonadas em face de circunstâncias várias, como a orfandade, a extrema pobreza, o desinteresse dos pais sanguíneos, e toda a sorte de desajustes sociais que desencadeiam o desmantelamento da família (RIZZARDO, 2006, p. 532).

É consabido, então, que o instituto da adoção é permeado por uma carga enorme de ideias equivocadas ou erroneamente concebidas, sem nenhuma base científica ou social, como o sentimento de que o adotado, logo no início ou no decorrer da convivência, causará problemas, que a criança, por este estado (adotada), será tratada com preconceitos, por isso sua origem é escondida. Há, ainda, a impressão de que a adoção é somente cabível em momento de forte carência familiar, por exemplo, em casos de morte de um filho.

A origem biológica da criança, no inconsciente das pessoas, é preocupante devido ao seu comportamento futuro ou aos desvios de conduta. Há também o receio de que a criança, ao saber de sua ascendência, adquira uma série de problemas em termos de aceitação do estado, ou seja, na condição de adotada.

Tudo isso, somado ao fato de que a maioria dos adotantes prefere as crianças de mais tenra idade, justamente para tornar a criança mais educável, moldável e adaptável ao modus vivendi da família adotiva: "Em nossos dias, a adoção ainda é uma questão delicada. Exaltada por uns como solução para os problemas sociais que assolam nossa infância ou vista por outros, estritamente como solução para a ausência de prole, o fato é que prevalece na adoção o desejo de imitar a biologia." (VIEIRA, 2004, p. 45).

Percebe-se, ainda, que a preferência do adotante nacional seja condicionada a algumas preferências, por exemplo, que ressalta o sexo feminino, ligada à ideia de que meninas naturalmente são mais sensíveis e dóceis, confrontadas com meninos com suposta tendência à rebeldia e, assim, com mais um fator dificultador de criar e educar (VIEIRA, 2004).

Muito se discute, projeta e planeja em sede da necessidade de programas governamentais mais eficazes voltados para o controle mais ostensivo da natalidade, entendendo-se que este é um dos fatores da proliferação do abandono dos infantes tanto nas ruas como em sua manipulação, exploração e maus-tratos.

A miséria, a desinformação, o preconceito e os velhos estereótipos arraigados por meio das décadas fazem que o instituto, por vezes, siga caminhos desviados da legalidade ou eivados de vícios no processo.

É importante lembrar-se de que a institucionalização do acolhimento, do abrigo e, após um período, a devolução da criança à sociedade, entendendo o Estado que o menor está pronto para a integração, não têm tido bom resultado nessa expectativa. Isso ocorre porque, no contexto geral, como salientado acima, a criança vai ou permanece na rua por outros motivos mais variados, e a internação, por suas próprias características, não lhe oferece carinho, segurança e estimulação necessários, tendo em vista que esses sentimentos só encontráveis em um meio familiar estável que apresente o mínimo de dignidade de sobrevivência. 


\section{A ADOÇÃO INTERNACIONAL COMO EXCEÇÃO}

A Convenção de Haia passou a viger em $1^{\circ}$ de maio de 1995 e foi ratificada em nosso País mediante o Decreto Legislativo 3.087/99. Em seu preâmbulo, os signatários "Reconhecendo que, para o desenvolvimento harmonioso de sua personalidade, a criança deve crescer em meio familiar, em clima de felicidade, de amor e de compreensão." (BRASIL, 1999, online). No mesmo tópico, está prescrito que o instituto de adoções internacionais "[...] pode apresentar a vantagem de dar uma família permanente à criança para quem não se possa encontrar uma família adequada em seu país de origem." (BRASIL, 1999, online).

$\mathrm{O}$ importante pacto ainda prescreve em seu artigo $4^{\circ}(\mathrm{b})$ :

As adoções abrangidas por esta Convenção só poderão ocorrer quando as autoridades competentes do Estado de origem: [...] b) tiverem verificado, depois de haver examinado adequadamente as possibilidades de colocação da criança em seu Estado de origem, que uma adoção internacional atende ao interesse superior da criança; (BRASIL, 1999, online).

A natureza subsidiária da adoção internacional fundamenta-se no bem-estar das crianças, as quais terão melhor qualidade de crescimento e formação em seu próprio seio familiar e em sua comunidade. No que é pertinente a esta modalidade, verifica-se que o ordenamento jurídico brasileiro a considera como medida extrema de colocação em família substituta, utilizada subsidiariamente para a adoção nacional. Portanto, é exceção na excepcionalidade.

Tanto é que é a pioneira norma sobre o assunto em sede internacional, Convenção sobre os Direitos da Criança (CDC), adotada pela ONU em 20 de novembro de 1989, ratificada por nosso País, como sua similar de Haia, em priorizar o ambiente da família, pois "[...] que os melhores interesses da criança estarão garantidos quando ela estiver com seus pais, sempre que possível." (HODGKIN; NEWELL, 2002, p. 295). Destaca-se também um importante mandamento normativo (art. 13) inscrito na Convenção sobre os Direitos da Criança (CDC) da Organização das Nações Unidas:

A remoção da criança do cuidado da família deve ser vista como medida de último recurso e pela menor duração possível. A decisão de remoção deve ser revista regularmente e o retorno da criança aos cuidados dos pais deve ser assegurado quando as causas originais de remoção tenham sido resolvidas ou tenham desaparecido. (ONU, 2007, CDC Art. 13).

Nossa Carta Magna admite o instituto adotivo, com a inscrição em seu artigo 227, $\S \S 5^{\circ}$ a $7^{\circ}$. O Estatuto da Criança e do Adolescente (ECA) dispõe também sobre a matéria. Neste consta que a adoção da criança em família estrangeira "deve ter o caráter excepcional" (art. 31) (BRASIL, 1990, online). Releva dizer que é uma das prerrogativas do Juiz ordenar que o casal adotante junte à petição a cópia da lei estrangeira ( $\left(2^{\circ}\right.$ do artigo 51$)$, tratando do tema para cotejamento com a nacional do adotando. A adoção é gratuita, e essa informação deve ser formalmente inscrita no pedido.

Tenha-se presente que, ao contrário de no passado, quando a criança e o adolescente 
eram objeto de Direito, hoje, são sujeitos de direitos, tendo o Estado, repise-se, a responsabilidade de ditar e assegurar as garantias disponíveis para a sua completa satisfação. Além disso, a adoção deve vir acompanhada da sedimentação de vínculos familiares necessariamente norteados pela reciprocidade, bem como atender aos primados dos superiores interesses da criança, como reafirmou Atalaio (2017, p. 50):

A adoção internacional, enquanto modalidade de adoção, tem também o superior interesse da criança como fim e deve também apresentar reais vantagens para o adotado. Contudo, com o objetivo de cumprir a sua finalidade, o superior interesse da criança tem várias especificidades nesta modalidade de adoção, inerentes à sua natureza.

Essa modalidade adotiva se reverte de caráter humanista, buscando proporcionar à criança ou ao adolescente um lar e uma família dignos e saudáveis. O caráter de prevalência a adotantes pátrios, por razões naturais e culturais, conforme o preceitua o estatuto menorista, apresenta que "toda criança ou adolescente tem direito a ser criado e educado no seio da sua família e, excepcionalmente, em família substituta [...]” (art. 19) (BRASIL, 1990, online). A substituição do meio paterno por alternativa: "a colocação em família substituta estrangeira constitui medida excepcional [...]" (art. 31) (BRASIL, 1990, online).

Outro fator a ser considerado é que, entre os brasileiros, geralmente, há a preferência por recém-nascidos, a escolha de etnia e, mais especial, o desapego a infantes com mais idade. Essa situação de escolha não acontece no instituto da adoção internacional, como destaca o pensamento de Kistemann (2008, p. 132):

Em contrapartida, os candidatos estrangeiros se mostram abertos para a adoção de crianças que não correspondem ao modelo idealizado de filho adotivo dos candidatos brasileiros. Suas expectativas são mais voltadas a uma forma possível de realização de seus papéis parentais, o que oportuniza a vigência enriquecedora e gratificante de uma recíproca troca de afeto. É claro que as possibilidades postas nestas adoções internacionais requerem considerável disponibilidade e preparação dos pais adotivos e eficácia da ação das entidades mediadoras.

Acerca dessa ideia, é fundamental comentar sobre a existência, em nosso País, do tráfico interno ou internacional de pessoas, com consequências nefastas comparáveis à subtração de menores para o Exterior.

Em nível de normativo internacional, o artigo 3º alínea "a", do Protocolo de Palermo (promulgado pelo Decreto n ${ }^{0}$ 5.017, de 12.03.2004), constitui "Tráfico de Pessoas":

[...] o recrutamento, o transporte, a transferência, o alojamento ou o acolhimento de pessoas, recorrendo à ameaça ou ao uso da força ou a outras formas de coação, ao rapto, à fraude, ao engano, ao abuso de autoridade ou de situação de vulnerabilidade ou à entrega ou aceitação de pagamentos ou benefícios para obter o consentimento de uma pessoa que tem autoridade sobre outra, para fins de exploração. A exploração deverá incluir, pelo menos, a exploração da prostituição de outrem ou outras formas de exploração sexual, o trabalho ou serviços forçados, a escravatura ou práticas similares à escravatura, a servidão ou a extração de órgãos (BRASIL, 2004, online). 
O Protocolo Adicional à Convenção da ONU contra o Crime Organizado relativo à prevenção, à repressão e à punição do tráfico de pessoas, foi ratificado pelo Brasil e promulgado pelo Decreto 5.017/04. Todavia, em que pese ao compromisso assumido pelo Brasil na órbita internacional, o tráfico de pessoas era reprimido criminalmente pelo ordenamento jurídico nacional apenas em sua forma de exploração sexual, por meio de crimes hospedados no próprio Código Penal (arts. 231 e 231-A do CP).

Essa modalidade criminosa já está inscrita no art. 239 do Estatuto da Criança e do Adolescente, conforme se vê: "promover ou auxiliar a efetivação de ato destinado ao envio de criança ou adolescente para o exterior com inobservância das formalidades legais ou com fito de obter lucro" (BRASIL, 1990, online), a sanção aplicável é de reclusão de 4 a 6 anos. Na lição de Jesus (2003, p. 140), "nada mais é do que uma forma moderna de escravidão". Segundo o Autor, o tráfico de crianças significa especificamente "o transporte, a acolhida de uma cidade para outra, ou para outro país, tendo por objetivo a exploração, a adoção ilegal, ou outras situações parecidas."

Com a edição da Lei no 13.344/16 (Lei de Tráfico de Pessoas) (BRASIL, 2016), o cenário mudou ao estabelecer mecanismos de prevenção e, sobretudo, de repressão ao tráfico de pessoas. Ficaram passíveis de punição ainda outras modalidades de exploração (trabalho escravo, remoção de órgãos, adoção ilegal e servidão), em harmonia com o disposto no artigo $3^{\circ}$ do Pacto de Palermo. As penalidades são mais rigorosas, com majorantes (1/3 a 1/2) inscritas no $\S 1^{\circ}$, em casos de:

I - o crime for cometido por funcionário público no exercício de suas funções ou a pretexto de exercê-las; II - o crime for cometido contra criança, adolescente ou pessoa idosa ou com deficiência; III - o agente se prevalecer de relações de parentesco, domésticas, de coabitação, de hospitalidade, de dependência econômica, de autoridade ou de superioridade hierárquica inerente ao exercício de emprego, cargo ou função; ou IV - a vítima do tráfico de pessoas for retirada do território nacional. (BRASIL, 2016, online, grifo nosso).

Confrontando essa situação com a adoção por estrangeiros, já advertia Dias (2009, online):

[...] faz-se necessário revitalizar o instituto da adoção. Mas para isso urge agilizar o seu processamento, pois a injustificável demora subtrai a possibilidade de crianças maiores serem adotadas. Mister desmistificar as adoções internacionais, como se estivesse fazendo tráfico de crianças, ou pior, venda de seus órgãos [...]. Quando todas as crianças tiverem um lar, um lar que não precisa copiar o modelo da sagrada família, quando a sociedade aprender a conviver com as diferenças, com certeza esse é um belo caminho para dar carinho, assegurar proteção e garantir a paz às crianças do mundo.

O decisório a seguir segue na mesma direção, quando favorece a adoção internacional de criança rejeitada pela mãe, em que o julgador compreende que a modalidade seguramente beneficia o adotando:

ADOÇÃO INTERNACIONAL - Pressupostos - Excepcionalidade - Cabimento mesmo havendo casais nacionais - A releitura da norma menorista não conduz à interpretação de que o casal estrangeiro, que preenche os pressupostos 
legais deva ser arredado, invariavelmente quando existem pretendentes nacionais, principalmente quando já desenvolveram forte afeto ao menor, cujo interesse deve ser preservado. Casos isolados que abalaram o instituto de adoção internacional, não devem servir como escusa para frustrar o pedido, sendo injusto obstar que o infante desfrute de melhor qualidade de vida em país desenvolvido. Inteligência dos artigos 28, 31 e 198, VII do ECA. Apelação provida." Decisão unânime (Ap. Cível 594039844 - 8ª̂am. Cível - TJRS - J. 26.05.1994 - rel. Des. José Carlos Teixeira Giorgis). (RIO GRANDE DO SUL, 1994, online, grifo nosso).

No tocante aos posicionamentos doutrinários de reserva à adoção externa e de cautela de práticas ilícitas como o tráfico de menores, tão corriqueiras no passado na esteira da adoção internacional, cabe o alerta abalizado da doutrinadora Diniz (2007, p. 503):

Seria mais conveniente [...] que se estabelecessem medidas eficazes para punir corruptos e traficantes, em vez de criar exigências para sua efetivação, visto que o estrangeiro está mais preparado psicológica e economicamente para assumir uma adoção, não fazendo discriminações atinentes à raça, ao sexo, à idade ou até mesmo à doença ou defeito físico que o menor possa ter; ao passo que o brasileiro é mais seletivo, pois, em regra, procura, para adotar, recém-nascido branco e sadio, surgindo, assim, em nosso país, problemas de rejeição social.

No mesmo passo, tem-se exemplo de Jurisprudência já remansosa sobre a adoção estrangeira (DINIZ, 2007, p. 509):

Ementa: Embora se trate de medida excepcional, é cabível a adoção internacional de menor que há muito se encontrava em estado de abandono e institucionalizado, sem receber visitas de sua genitora que não possui condições físicas e psicológicas para a criação daquele, agindo com omissão e negligência, mormente quando comprovado que os demais filhos também vivem em estado de desagregação familiar, à mercê de maus-tratos, abusos físicos e sexuais. Ap. 2003.001.29416 - Segredo de Justiça - 8a Câm. J. 18.12.2003 - rel. Desa. Odete Knaack de Souza - DORJ 03.06.2004.

A matéria já possuía disciplina em tratado internacional, sendo abordada pelo Protocolo Adicional à Convenção da ONU contra o Crime Organizado relativo à prevenção, à repressão e à punição do tráfico de pessoas, ratificado pelo Brasil e promulgado pelo Decreto 5.017/04. Todavia, em que pese ao compromisso assumido pelo Brasil na órbita internacional, o tráfico de pessoas era reprimido criminalmente pelo ordenamento jurídico nacional apenas em sua forma de exploração sexual, por meio de crimes hospedados no próprio Código Penal (arts. 231 e 231-A do CP).

A matéria já possuía disciplina em tratado internacional, sendo combatido pelo Protocolo Adicional à Convenção da ONU contra o Crime Organizado relativo à prevenção, repressão e punição do tráfico de pessoas, ratificado pelo Brasil e promulgado pelo Decreto 5.017/04. Todavia, em que pese o compromisso assumido pelo Brasil na órbita internacional, o tráfico de pessoas era reprimido criminalmente pelo ordenamento jurídico nacional apenas em sua forma de exploração sexual, por meio de crimes hospedados no próprio Código Penal (Arts. 231 e 231-A do CP) (CASTRO, 2016, online). 
É perceptível, portanto, que as adoções internacionais ocorrem em grande número e de forma crescente no território brasileiro. Após as exigências postas pelo Estatuto da Criança e do Adolescente e pelas reservas inscritas na Lei $n^{0} 13.344 / 2016$, esse processo legal se tornou mais seguro para as crianças e para os adolescentes os quais estão à espera de adoção.

\section{CONCLUSÃO}

A família natural, evidentemente, é o ambiente ideal para o crescimento da criança, pois é, no seio familiar que, além dos laços afetivos, há todo um ambiente sociocultural propício ao seu desenvolvimento físico e intelectual.

As condições indispensáveis à harmonia e à consolidação de um ambiente familiar são realidades existentes ao longo dos anos, em especial, no Nordeste de nosso País, fortemente influenciado por muitos condicionantes que minam e, por vezes, destroem o laço familiar necessário para criança.

As condições adversas do clima que depauperam a produção de alimentos suficientes à sustentação da vida levam à derrocada do tecido social, provocando o êxodo rural, a imigração e, consequentemente, a desestruturação básica da família original.

A busca mínima de sobrevivência leva, de várias maneiras, ao surgimento das mais variadas formas de proteção da criança, seja pela prática de "dar para criar" a outras famílias, largando-a em instituições (herança da medieval "roda dos expostos"), seja simplesmente pela transferência/remoção do infante a qualquer lugar e a qualquer destino.

Quando as condições necessárias para o cuidado da criança não estão presentes, surge o instituto da adoção como medida supridora dessa carência. A preferência de sua aplicação, no país nativo, é perfeitamente justificável e tem prevalência à internacional, com normas regedoras e garantidoras dessa situação.

A natureza optativa da adoção internacional teve sua síntese durante a realização do XIII Congresso da Associação Internacional de Magistrados de Menores e de Família, acontecido em Turim (Itália), no período de 16 a 21 de setembro de 1990, com a recomendação: "Que seja confirmado o caráter subsidiário da adoção internacional à qual se poderá recorrer somente depois de esgotadas todas as possibilidades de manutenção da criança na própria família ou em outra família no seu país de origem." (CONGRESSO DA ASSOCIAÇÃO INTERNACIONAL DE MAGISTRADOS DE MENORES E DE FAMÍLIA, 13., 1999 apud HOUDALI; PIRES, 2009, online).

A adoção internacional, como exceção, cercada de todas as cautelas legais, configura-se como a possibilidade de oferecer a crianças e a adolescentes a oportunidade de terem um futuro promissor, com o sentimento de pertencerem a uma família, na certeza de que terão melhores condições de vida ao contrário dos que crescem em orfanatos ou são deixados à própria sorte e condenados ao que o imponderável destino venha lhes proporcionar.

Saliente-se, por fim, que o interesse internacional na adoção não se deve resumir somente na satisfação do adotante em oferecer um lar ao infante desamparado em seu meio social, devendo priorizar por estarem presentes a visão e a salvaguarda do Direito Internacional, 
no sentido de manter a incolumidade jurídica das novas relações afetivas que envolvem o novo núcleo familiar diante das diferenças socioculturais presentes, a fim de velar e garantir sempre o interesse e a proteção do adotando.

\title{
ABANDONMENT AND ADOPTION AS FUNDAMENTAL RIGHTS AND INTERNATIONAL ADOPTION AS AN EXCEPTION IN BRAZILIAN NORTHEAST
}

\begin{abstract}
This article deals with the institute of adoption as a fundamental right and international adoption as an exception, considering, more specifically, the situation of the abandoned children in Northeastern Brazil. It addresses the possible damages caused by the institutionalization, reflected directly in the society, since the child who lives in shelters suffers from the limitation or even absence of values, stimuli, coexistence and safety, the latter being a fundamental right of the child. It contextualizes the adverse and hostile social environment of the Northeast Region of the country. It highlights the misery of the families in the Northeast Region, which, often without alternative, leave their children at the doors of houses or shelters, or abandon them in hospitals or health centers. It considers adoption as an exceptional institute to integrate children and adolescents into a stable and safe family life, and refers to the set of laws dealing with the matter: the Convention on the Rights of the Child (CRC), the 1988 National Constitution and the Child and Adolescent Statute (ECA). Finally, it concludes that international adoption, as an exception and surrounded by legal precautions, offers abandoned children and adolescents a promising future, in addition to better raising conditions compared to orphanages and a reduced waiting time for family reintegration. Unlike the more selective Brazilian adopters, the adoption by foreigners is free of prejudice and preferences.
\end{abstract}

Keywords: Human Rights. Abandonment. Institutionalization. Adoption. Exception. International Adoption. Tendency. Northeastern Brazil.

\section{ABANDONO Y ADOPCIÓN COMO DERECHOS FUNDAMENTALES Y ADOPCIÓN INTERNACIONAL COMO EXCEPCIÓN EN EL NORDESTE BRASILEÑO}

\section{RESUMEN}

Este artículo trata del instituto de la adopción como derecho fundamental y de la adopción internacional como excepción, considerando, más específicamente, la situación del menor abandonado en el Nordeste brasileño. La metodología utilizada contempló investigación bibliográfica con análisis de obras, de la legislación y de datos estadísticos. Trata de los posibles daños causados por la institucionalización, refletados directamente en la sociedad, porque 
el niño insertado en refugios sufre con la limitación o, incluso, con la ausencia de valores, estímulos, convivencia y seguridad, esta última siendo un derecho fundamental del infante. Contextualiza el medio social adverso y hostil de la región Nordeste del país. Destaca la condición de penuria de las familias nordestinas, que, muchas veces sin alternativa, dejan a los hijos en puertas de residencias, abrigos, o los abandonan en hospitales o puestos de salud. Entiende la adopción como instituto excepcional para integrar el niño y el adolescente a la convivencia familiar estable y segura y se refiere al conjunto normativo que trata de la materia: la Convención sobre los Derechos del Niño (CDC), la Constitución Nacional de 1988 y el Estatuto del Niño y del Adolescente (ECA). Concluye que la adopción internacional, como excepción, rodeada de las cautelas legales, ofrece a niños y adolescentes abandonados un futuro prometedor, además de mejores condiciones de crecimiento en comparación a los orfanatos y reducción del tiempo de espera para reintegración familiar. Diferentemente de los adoptantes brasileños, que son más selectivos, la adopción hecha por extranjeros es libre de prejuicios y sin preferencias.

Palabras clave: Derechos Humanos. Abandono. Institucionalización. Adopción. Excepción. Adopción Internacional. Tendencia. Nordeste brasileño.

\section{REFERÊNCIAS}

ALMEIDA, Júlio Alfredo de. Adoção Intuitu Personae: uma proposta de agir. Revista do Ministério Público do Rio Grande do Sul, Porto Alegre, n. 54, p. 189-218, out. 2004. Disponível em: <http://intra.mp.rs.gov.br/areas/biblioteca/arquivos/acervos/revista_do_ mprs/1970_em_diante/n54/56854.pdf> Acesso em: 21 out. 2018.

ALVES, Graziella Ferreira. Adoção no Brasil à luz do neoconstitucionalismo. 2011. 207 f. Dissertação (Mestrado em Direito Público) - Universidade Federal de Uberlândia, Uberlândia, 2011. Disponível em: <https://repositorio.ufu.br/bitstream/123456789/13180/1/d. pdf $>$. Acesso em: 9 maio 2018.

ATALAIO, Rafael José Esteves. A adoção internacional e o superior interesse da criança. 2017. 70 f. Dissertação (Mestrado Profissionalizante em Ciências Jurídico-Forenses) -Faculdade de Direito da Universidade de Lisboa, Lisboa, 2017. Disponível em: <http://repositorio.ul.pt/bitstream/10451/32500/1/ulfd134474_tese.pdf>. Acesso em: 10 maio 2018.

BODZIAK, Fernando Wolff. Adoção: Inovações trazidas pela Lei n. 12.010/09. Revista Jurídica Consulex, Brasília, v. 14, n. 334, p. 30-31, dez. 2010.

BRASIL. Constituição (1988). Constituição da República Federativa do Brasil de 1988. Presidência da República, Brasília, DF, 1988. Disponível em: <http://www.planalto.gov. br/ccivil_03/Constituicao/Constituicao.htm>. Acesso em: 10 maio 2018.

. Decreto $n^{\circ}$ 99.710/1990. Promulgação da Convenção sobre os Direitos da Criança. 
Presidência da República, Brasília, DF, 1990. Disponível em: < http://www.planalto.gov.br/ccivil_03/decreto/1990-1994/d99710.htm>. Acesso em: 10 maio 2018.

. Lei no 8.069, de 13 de julho de 1990. Dispõe sobre o Estatuto da Criança e do Adolescente e dá outras providências. Presidência da República, Brasília, DF, 1990. Disponível em: <http://www.planalto.gov.br/CCivil_03/Leis/L8069.htm>. Acesso em: 10 maio 2018.

. Decreto n 3.087, de 21 de junho de 1999. Promulga a Convenção Relativa à Proteção das Crianças e à Cooperação em Matéria de Adoção Internacional, concluída na Haia, em 29 de maio de 1993. Presidência da República, Brasília, DF, 1999. Disponível em: < http://www.planalto.gov.br/CCivil_03/decreto/D3087.htm>. Acesso em: 10 maio 2018.

. Superior Tribunal de Justiça. Recurso Especial no 469914/RS. Relator: Ministro Ruy Rosado de Aguiar. Data de Julgamento: 4 de fevereiro de 2003. T4 - Quarta Turma. STJ Jus Brasil, 4 fev. 2003. Disponível em: <https://stj.jusbrasil.com.br/jurisprudencia/249988/recurso-especial-resp-469914-rs-2002-0123592-2>. Acesso em: 10 maio 2018.

. Decreto $\mathrm{n}^{\mathrm{0}}$ 5.017, de 12 de março de 2004. Promulga o Protocolo Adicional à Convenção das Nações Unidas contra o Crime Organizado Transnacional Relativo à Prevenção, Repressão e Punição do Tráfico de Pessoas, em Especial Mulheres e Crianças. Presidência da República, Brasília, DF, 2004. Disponível em: <http://www.planalto.gov. br/ccivil_03/_ato2004-2006/2004/decreto/d5017.htm>. Acesso em: 10 maio 2018.

. Lei $\mathrm{n}^{\circ}$ 13.344, de 6 de outubro de 2016. Dispõe sobre prevenção e repressão ao tráfico interno e internacional de pessoas e sobre medidas de atenção às vítimas. Presidência da República, Brasília, DF, 2016. Disponível em: < http://www.planalto.gov.br/CCivil_03/_Ato2015-2018/2016/Lei/L13344.htm>. Acesso em: 10 maio 2018.

. Lei $\mathrm{n}^{\circ}$ 13.509, de 22 de novembro de 2017. Dispõe sobre adoção e altera a Lei $\mathrm{n}^{\circ} 8.069$, de 13 de julho de 1990 (Estatuto da Criança e do Adolescente). Presidência da República, Brasília, DF, 2017. Disponível em: <http://www.planalto.gov.br/ccivil_03/_Ato2015-2018/2017/Lei/ L13509.htm>. Acesso em: 10 maio 2018.

CASTRO, Henrique Hoffmann Monteiro de. Lei de Tráfico de Pessoas traz avanços e causa perplexidade. Consultor Jurídico, 11 out. 2016. Disponível em: < https://www.conjur.com.br/2016-out-11/academia-policia-lei-trafico-pessoas-traz-avancos-causa-perplexidade $>$. Acesso em: 10 maio 2018.

COSTA, Tereza Maria Machado Lagrota. Adoção por Pares homoafetivos: uma abordagem jurídica e psicológica. Disponível em: < http://intranet.viannajr.edu.br/revista/dir/ doc/art_10005.pdf>. Acesso em: 9 ago. 2018.

CUNEO, Mônica Rodrigues. Abrigamento prolongado: os filhos do esquecimento. A institucionalização prolongada de crianças e as marcas que ficam. In: RIO DE JANEIRO 
(Estado). Ministério Público do Estado do Rio de Janeiro. Censo da População Infanto-juvenil Abrigada do Estado do Rio de Janeiro. Rio de Janeiro, 2009. p. 415-432.

DIAS, Maria Berenice. Manual de direito das famílias. Porto Alegre: Livraria dos Advogados, 2005.

. Paz para a Infância do Mundo. 2009. Disponível em: $<$ http://investidura.com. br/biblioteca-juridica/artigos/direito-civil/2327-paz-para-a-infancia-no-mundo $>$. Acesso em: 26 abr. 2018.

. O lar que não chegou. Revista IOB de Direito de Família, Porto Alegre, v. 11, n. 57, p. 12-15, dez.jjan. 2010.

DINIZ, Maria Helena. Curso de direito civil brasileiro: direito de família. 22. ed. São Paulo: Saraiva, 2007.

FACHINETTO, Neidemar José. A garantia do direito à convivência familiar e sua relação com as políticas públicas: uma análise transdisciplinar. 2008. 98 f. Dissertação (Mestrado em Direito) - Universidade de Santa Cruz do Sul, Santa Cruz do Sul, 2008. Disponível em: <http://www.dominiopublico.gov.br/download/teste/arqs/cp060744.pdf>. Acesso em: 27 abr. 2018.

HISTÓRICO das secas no Brasil depois do ano 1500. 2014. Disponível em: < http://www.aguasdemare.com.br/historico-das-secas-no-brasil-depois-do-ano-1500/>. Acesso em: 10 maio 2018.

HODGKIN, R.; NEWELL, P. Implementation Handbook for the Convention on the Rights of the Child. Geneva: UNICEF, 2002.

HOUDALI, Amira Samih Hamed Mohd; PIRES, Victor Paulo Kloeckner. A adoção internacional e suas diretrizes no direito brasileiro. Âmbito Jurídico, Rio Grande, XII, n. 64, maio 2009. Disponível em: < http://www.ambitojuridico.com.br/site/index. php/abrebanner.php?n_link=revista_artigos_leitura\&artigo_id $=6110 \&$ revista_caderno $=14>$. Acesso em: 10 maio 2018.

INSTITUTO BRASILEIRO DE GEOGRAFIA E ESTATÍSTICA. População idosa no Brasil cresce e diminui número de jovens, revela Censo. 2011. Disponível em: $<$ http:// www.brasil.gov.br/noticias/educacao-e-ciencia/2011/04/populacao-idosa-no-brasil-cresce-e-diminui-numero-de-jovens-revela-censo >. Acesso em: 9 maio 2018.

INSTITUTO DE PESQUISA ECONÔMICA APLICADA. O perfil da criança e do adolescente nos abrigos pesquisados. 2012. Disponível em: <http://repositorio.ipea.gov.br/ bitstream/11058/3050/4/Livro_cap.\%202>. Acesso em: 10 maio 2018.

JESUS, Damásio de. Tráfico Internacional de mulheres e crianças: Brasil: aspectos regionais e nacionais. São Paulo: Saraiva, 2003.

KISTEMANN, Flávia Aparecida. Adoção internacional: uma possibilidade de inclusão 
familiar. 2008. 165 f. Tese (Doutorado em Serviço Social) - Pontifícia Universidade Católica de São Paulo, São Paulo, 2008. Disponível em: < https://sapientia.pucsp.br/bitstream/ handle/17902/1/Flavia\%20Aparecida\%20Kistemann.pdf>. Acesso em: 9 maio 2018.

LIMA, Fernanda da Silva; VERONESE, Josiane Rose Petry. Direito da Criança e do Adolescente: a necessária efetivação dos direitos fundamentais. Florianópolis: Fundação Boiteux, 2012. v. 5. Disponível em: <https://repositorio.ufsc.br/bitstream/handle/123456789/99635/VD-Direito-da-Crianca-18-09-2012.pdf?sequence=1>. Acesso em: 27 abr. 2018.

MARCÍLIO, Maria L. História social da criança abandonada. São Paulo: Hucitec, 1998.

MILLER, J. G. Toughts on institucional abuse. Legal response: child advocacy and protection, v. 2, n. 3, p. 13, 1981.

ORGANIZAÇÃO DAS NAÇÕES UNIDAS. Pobreza permanece concentrada no Norte e no Nordeste do Brasil, diz estudo de centro da ONU. 2016. Disponível em:

$<$ https://nacoesunidas.org/pobreza-permanece-concentrada-no-norte-e-no-nordeste-do-brasil-diz-estudo-centro-onu/>. Acesso em: 9 ago. 2018.

. Comissão de Direitos Humanos [UNCHR]. Report of the Working group on the Question of a Draft Convention on the Rights of the Child. UN Doc. E.CN.4/1989/48. 2 mar. 1989.

. Convenção de Haia relativa à Proteção das Crianças e à Cooperação em Matéria de Adoção Internacional. 29 maio 1993.

PILOTTI, F.; RIZZINI, I. A arte de governar crianças: a história das políticas sociais, da legislação e da assistência à infância no Brasil. Rio de Janeiro: Amais, 1995.

RIO GRANDE DO SUL. Apelação Cível 594039844, de 26 de maio de 1994. $8^{\text {a }}$ Câm. Cível/TJRS. Relator: Des. José Carlos Teixeira Giorgis. TJ RS, 26 maio 1994. Disponível em: <https://tj-rs.jusbrasil.com.br/jurisprudencia/9234518/apelacao-civel-ac-594039844-rs-tjrs>. Acesso em: 10 maio 2018.

RIZZARDO, Arnaldo. Direito de Família: Lei n. 10.406, de 10/01/2002. 4. ed. Rio de Janeiro: Forense, 2006.

RODRIGUES, Emerson Alexandre Molina. O Reconhecimento da Paternidade por Socioafetividade e seus Efeitos Jurídicos. 2005. 287 f. Dissertação (Mestrado em Direito) - Pontifícia Universidade Católica, São Paulo, 2005. Disponível em: <https://sapientia. pucsp.br/bitstream/handle/7553/1/Emerson\%20Alexandre\%20Molina\%20Rodrigues. pdf>. Acesso em: 26 abr. 2018.

VETTORAZZO, Lucas. Cerca de 13 milhões ainda vivem em pobreza extrema no Brasil, diz IBGE. Jornal Folha de São Paulo, São Paulo, 15 dez. 2017. Disponível em: < https:// 
www1.folha.uol.com.br/mercado/2017/12/1943549-cerca-de-13-milhoes-ainda-vivem-em-pobreza-extrema-no-brasil-diz-ibge.shtml>. Acesso em 9 ago. 2018.

VIEIRA, Joice Melo. Adoção em matizes: os filhos que queremos são os que podemos ter? Revista da Universidade Federal de Goiás, v. 6, n. 2, p. 42-45, 2004. Disponível em: < https://www.revistas.ufg.br/revistaufg/article/view/48740/23933 >. Acesso em: 26 abr. 2018.

WELTER, Belmiro Pedro. Inconstitucionalidade do processo de adoção judicial. 2005. Disponível em: < http://www.buscalegis.ufsc.br/revistas/files/anexos/8200-8199-1-PB. htm >. Acesso em: 26 abr. 2018. 